\title{
The Current Status of Vaccine Uptake and the Impact of COVID-19 on Intention to Vaccination in Patients with COPD in Beijing
}

\author{
Zhu Song $\mathbb{D}^{1, *}$ \\ Xiaofang $\mathrm{Liu}^{2, *}$ \\ Pingchao Xiang ${ }^{3, *}$ \\ Yingxiang $\operatorname{Lin}^{4, *}$ \\ Li Dai ${ }^{5, *}$ \\ Yanfei Guo ${ }^{6, *}$ \\ Jiping Liao ${ }^{7, *}$ \\ Yahong Chen' \\ Ying Liang' \\ Yongchang Sun'
}

'Department of Respiratory and Critical Care Medicine, Peking University Third Hospital,

Beijing, 100191, People's Republic of China;

${ }^{2}$ Department of Respiratory and Critical Care

Medicine, Beijing Tongren Hospital, Capital

Medical University, Beijing, 100730, People's

Republic of China; ${ }^{3}$ Department of Respiratory

and Critical Care Medicine, Peking University

Shougang Hospital, Beijing, I00I44, People's

Republic of China; ${ }^{4}$ Department of Respiratory

and Critical Care Medicine, Beijing Chaoyang

Hospital, Capital Medical University, Beijing,

100020, People's Republic of China;

${ }^{5}$ Department of Respiratory and Critical Care

Medicine, Beijing Jishuitan Hospital, Beijing,

100035, People's Republic of China;

${ }^{6}$ Department of Respiratory and Critical Care Medicine, Beijing Hospital, National Center of Gerontology, Institute of Geriatric Medicine, Chinese Academy of Medical Sciences, Beijing, 100730, People's Republic of China;

7Department of Respiratory and Critical Care Medicine, Peking University First Hospital,

Beijing, 100034, People's Republic of China

*These authors contributed equally to this work

Correspondence: Yongchang Sun; Ying Liang Department of Respiratory and Critical Care Medicine, Peking University Third Hospital,

North Garden Road 49, Haidian District,

Beijing, People's Republic of China

Tel +86 I39 10979132

Fax+861082266989

Email suny@bjmu.edu.cn;

bysyliangying@126.com
Background: SARS-CoV-2 tends to cause more severe disease in patients with COPD once they are infected. We aimed to investigate the rates of influenza, pneumococcal and COVID19 vaccination uptake in patients with COPD and to determine whether the COVID-19 pandemic and widespread vaccination against COVID-19 had any impact on the intention to accept influenza vaccines in these patients.

Methods: We conducted a multi-center and cross-sectional survey in seven tertiary hospitals in Beijing and consecutively recruited outpatients with COPD from June 1st to July 30th, 2021. The survey included patient's clinical characteristics, uptake of influenza, pneumococcal and COVID-19 vaccination, vaccine knowledge, attitude towards vaccines, and the change of intention to receive influenza vaccination after COVID-19 epidemic and COVID19 vaccination in Beijing.

Results: A total of 264 patients were enrolled. The rate of COVID-19 vaccination during the study period was $39.0 \%$. The rates of influenza vaccination in the past season and pneumococcal vaccination in the past year were $22.7 \%$ and $5.7 \%$, respectively. Of the patients who had not received COVID-19 vaccination $(\mathrm{n}=161)$, only $16.2 \%$ reported that COVID-19 vaccination was recommended by clinicians, while $23.5 \%$ had no knowledge regarding COVID-19 vaccination. About $51.1 \%$ of the patients reported that their intention to receive influenza vaccination was influenced by the COVID-19 pandemic. COVID-19 vaccination was independently associated with a positive change in intention to receive influenza vaccination.

Conclusion: The coverage rate of COVID-19 vaccination among patients with COPD in Beijing was $39.0 \%$, and that of influenza and pneumococcal vaccination was very low. The COVID-19 pandemic and the COVID-19 vaccination campaign showed a significant, positive impact on patients with COPD in terms of influenza vaccination. Improving awareness of the effectiveness and safety of vaccines among both healthcare professionals and patients could increase vaccination coverage in patients with COPD.

Keywords: chronic obstructive pulmonary disease, vaccines, COVID-19, knowledge, attitude

\section{Introduction}

Chronic obstructive pulmonary disease (COPD), characterized by persistent airflow limitation, is the third leading cause of death worldwide, ${ }^{1}$ accounting for the highest morbidity and mortality among all the chronic respiratory diseases. ${ }^{2}$ COPD is still projected to lead to substantial economic and social burdens. ${ }^{3}$ Acute exacerbation of COPD is one of the major events during the natural course of the disease, associated with deterioration of health status, increasing hospitalization and 
readmission, and poor prognosis. Therefore, prevention of subsequent exacerbations is a major goal of the disease management. $^{3}$

Exacerbations of COPD are commonly triggered by respiratory virus infections, ${ }^{4}$ including influenza, ${ }^{5}$ while bacterial infections are other common causes. ${ }^{6}$ Vaccination is the most effective measure to prevent influenza infection. ${ }^{7}$ Recent studies have demonstrated the protective role of influenza vaccination in COPD patients, with a significant reduction in the risk of exacerbation and influenza-related hospitalization. ${ }^{8,9}$ In addition, studies also showed that pneumococcal vaccinations could reduce the likelihood of exacerbation and community-acquired pneumonia among COPD patients. ${ }^{10}$ According to the Global Initiative for Chronic Obstructive Lung Disease (GOLD) guidelines, influenza vaccination is recommended for all COPD patients and pneumococcal vaccination is recommended for all patients aged $>65$ years. ${ }^{3}$ However, the coverage of influenza vaccination was still very low among patients with COPD in China, ranging from $0.9 \%$ to $3.6 \% .{ }^{11-13}$ In some developed countries, the coverage of influenza vaccination in COPD populations ranged from $47.9 \%$ to $62.7 \%{ }^{14-17}$ Similarly, the coverage of pneumococcal vaccination in China was also low, ranging from $0.8 \%$ to $30.4 \% .^{12,18,19}$ A lack of perception of the threat from infections, distrust of the effectiveness of vaccines, fear of side effects, and lack of physician recommendations were the major reasons for individuals against vaccination. ${ }^{20-23}$

Severe acute respiratory syndrome coronavirus 2 (SARS-CoV-2), which is responsible for the coronavirus disease 2019 (COVID-19) pandemic, tends to cause more severe disease in patients with COPD once they are infected. $^{24,25}$ Clinical trials have demonstrated the effectiveness and safety of several types of COVID-19 vaccines in preventing SARS-CoV-2 infection, ${ }^{26-28}$ and therefore vaccination for patients with COPD may need to be prioritized for prevention of infection and/or reduction of severe cases. Inactivated COVID-19 vaccines started to be widely used in adult populations in mainland China since the early 2021. During the initial phase of the mass vaccination against COVID-19 in China, those over 60 years old were not covered because of the lack of evidence from clinical trials in this population. Moreover, the coverage rate of COVID-19 vaccination in patients with COPD and their attitude towards COVID-19 vaccination have not been investigated. In addition, whether the COVID-19 epidemic in Beijing in early 2020 and the widespread vaccination against COVID-19 had any impact on the acceptance of influenza and pneumococcal vaccines was unknown.

To address these questions, we performed an outpatient-based survey of the current status of influenza, pneumococcal and COVID-19 vaccination uptake, as well as the relevant knowledge and the attitude towards vaccination, in patients with COPD from seven tertiary hospitals in Beijing. We hypothesized that COVID-19 and the mass vaccination against COVID-19 would have a positive impact on the intention to receive influenza vaccines in patients with COPD.

\section{Methods}

\section{Study Design and Subjects}

We conducted a multi-center and cross-sectional anonymous survey in the Respiratory Outpatient Clinics in seven tertiary hospitals (Peking University Third Hospital, Beijing Tongren Hospital, Peking University Shougang Hospital, Beijing Chaoyang Hospital, Beijing Jishuitan Hospital, Beijing Hospital, Peking University First Hospital) in Beijing and consecutively recruited patients with COPD from June 1st to July 30th, 2021. All the patients met the diagnosis of COPD according to Global Initiative for Chronic Obstructive Lung Disease (GOLD 2021) guidelines and had definite airflow limitation with a post-bronchodilator forced expiratory volume in 1 second (FEV1)/forced vital capacity (FVC) $<0.7$. $^{3}$ Each patient was recruited once.

Exclusion criteria included: 1) age $<40$ years; 2) mental diseases; 3) cognitive dysfunction such as vascular dementia or Alzheimer's disease; 3) refusal to participate in this study.

The study protocol was approved by the Independent Ethics Committee of the Peking University Third Hospital (IRB00006761-M2021379) which was the primary research institution of the present study. Written informed consents were obtained from the subjects or their close relatives.

\section{Questionnaire Design and Data Collection}

A standard questionnaire was designed by group discussion with experts from each center. All the clinicians participating in this survey were invited to attend a centralized training session, which was conducted by the primary research institution, Department of 
Respiratory and Critical Care Medicine of Peking University Third Hospital. Any identifier to an individual patient, such as identification number and full name, was not collected. The data were analyzed anonymously.

The questionnaire consisted of the following sections:

Demographic information: gender, age, ethnicity, permanent residence, employment status, education level, medical insurances, and smoking status.

Respiratory symptoms, comorbidities and medications for COPD: Respiratory symptoms were assessed by the modified Medical Research Council (mMRC) dyspnea scale. ${ }^{29}$ Comorbidities including cardiovascular diseases, diabetes, malignancies, chronic renal or liver diseases and autoimmune diseases were collected. Medications for COPD included inhaled short-acting $\beta$-agonist (SABA), inhaled short-acting muscarinic antagonist (SAMA), inhaled corticosteroids plus long-acting $\beta$-agonist (ICS/ LABA), long-acting muscarinic antagonist (LAMA), LABA/LAMA and LABA/LAMA/ICS (fixed-dose triple therapy).

Vaccination uptake and knowledge of and intention to vaccination: This section included the following items: 1 ) History of influenza and pneumococcal vaccination; 2) The reason why an individual did not accept seasonal influenza vaccine/pneumococcal vaccine; 3) Knowledge of vaccinations; 4) COVID-19 vaccination; 5) The potential impact of the COVID-19 epidemic and COVID-19 vaccination on the intention to influenza vaccination. The details of the above items are shown in Figure 1.

\section{Statistical Analysis}

Continuous variables were expressed as mean \pm standard deviation (SD). Categorical variables were expressed as numbers (\%). Chi-square test or Fisher's exact test was performed for categorical variables in univariate analysis. Binary logistic regression analysis was performed to assess the independent relation between the change of intention to influenza vaccination after COVID-19 epidemic and COVID-19 vaccination and the relevant factors. In this model, the change of intention to influenza vaccination was the dependent variable and converted to a binary variable, which was recorded as "Yes" or "No". The independent variables associated with the change of intention to influenza vaccination with $P<0.1$ in the univariate analysis were also converted to binary variables and then included in multivariate analysis. Statistical analyses were performed using SPSS software, version 19.0 (IBM, Armonk, NY, USA). Results were considered statistically significant at $P<0.05$.

\section{Results}

\section{Baseline Characteristics of the Study Subjects}

We initially recruited 282 patients with definite COPD from June 1st to July 30th, 18 of whom refused to participate in this survey. Finally, a total of $264(93.6 \%)$ patients who completed the questionnaire were enrolled for analysis. The mean age was $68.4( \pm 8.8)$ years and $89.4 \%$ were male. Most of the patients were urban residents (93.6\%) and had retired $(83.3 \%) .61 .0 \%$ of the patients had middle school education and $14.0 \%$ had university education or higher. Only 14 patients $(5.3 \%)$ had no medical insurance, while the others had various kinds of medical insurances or free medical care. Of all the patients, $26.5 \%$ were current smokers and $60.6 \%$ were ex-smokers, with a smoking index of $35.0( \pm 21.8)$ pack-years. Four patients $(1.5 \%)$ ever experienced COVID-19 infection during the epidemic. Cardiovascular diseases (32.6\%) and diabetes (15.2\%) were the most common comorbidities. More than $80.0 \%$ (216/264) received long-term inhaled medications for COPD and 76.1\% (201/264) had maintained their medications as prescribed. ICS/LABA (56.0\%) and LAMA (48.6\%) were the most commonly used pharmacological therapy. The proportions of LABA/LAMA and LABA/LAMA/ICS fixeddose therapy were $10.2 \%$ and $13.4 \%$, respectively (Table 1 ).

\section{The Rates of Influenza, Pneumococcal and COVID-19 Vaccination in Patients with COPD}

$22.7 \%$ of the patients $(60 / 264)$ received influenza vaccination in the past season $(2020 / 2021)$, while only $5.7 \%(15 / 264)$ received pneumococcal vaccination in the past year (Table 2). Among the patients aged $\geq 60$ years $(n=221)$, the uptake rate of influenza vaccination in the past season was $24.4 \%$. Among the patients aged $\geq 65$ years $(n=189)$, the uptake rate of pneumococcal vaccination in the past year was $5.8 \%$.

During the study period, 103 (39.0\%) patients reported that they had received COVID-19 vaccination (Table 2).

\section{Knowledge of and Attitude Towards Influenza and Pneumococcal Vaccinations}

Of all the patients, $44.3 \%(117 / 264)$ and $38.6 \%(102 / 264)$ were aware of the benefits of influenza and pneumococcal vaccinations for individuals with COPD, respectively. 151 (57.2\%) patients knew that influenza vaccination was free for individuals aged $\geq 60$ years in Beijing. 112 (42.2\%) and 


\begin{tabular}{|c|c|}
\hline Items & Options \\
\hline \multicolumn{2}{|l|}{ 1) History of influenza and pneumococcal vaccination } \\
\hline $\begin{array}{l}\text { Did you receive seasonal influenza vaccines in the past } \\
\text { season }(2020 / 2021) \text { ? }\end{array}$ & $\begin{array}{l}\square \text { Yes } \\
\square \text { No }\end{array}$ \\
\hline Did you receive pneumococcal vaccines in the past year? & $\begin{array}{l}\square \text { Yes } \\
\square \quad \text { No }\end{array}$ \\
\hline $\begin{array}{l}\text { 2) The reason why an individual did not accept seasonal } \\
\text { influenza vaccines? }\end{array}$ & $\begin{array}{l}\square \text { worry about the side effects } \\
\square \text { do not think the vaccines necessary } \\
\square \text { activity inconvenience } \\
\square \text { own expense for vaccination } \\
\square \text { others }\end{array}$ \\
\hline $\begin{array}{l}\text { The reason why an individual did not accept } \\
\text { pneumococcal vaccines? }\end{array}$ & $\begin{array}{l}\square \text { worry about the side effects } \\
\square \text { do not think the vaccines necessary } \\
\square \text { activity inconvenience } \\
\square \text { own expense for vaccination } \\
\square \text { others }\end{array}$ \\
\hline \multicolumn{2}{|l|}{ 3) Knowledge of vaccinations } \\
\hline $\begin{array}{l}\text { Did you know the benefit of influenza vaccines for } \\
\text { individuals with COPD? }\end{array}$ & $\begin{array}{l}\square \text { Yes } \\
\square \text { No }\end{array}$ \\
\hline $\begin{array}{l}\text { Did you know that influenza vaccination was free for } \\
\text { individuals aged } \geq 60 \text { years in Beijing? }\end{array}$ & $\begin{array}{l}\square \text { Yes } \\
\square \text { No }\end{array}$ \\
\hline $\begin{array}{l}\text { Did any medical staffs ever recommend the seasonal } \\
\text { influenza vaccines to you? }\end{array}$ & $\begin{array}{l}\square \text { Yes } \\
\square \text { No }\end{array}$ \\
\hline $\begin{array}{l}\text { Did you know the benefit of pneumococcal vaccines for } \\
\text { individuals with COPD? }\end{array}$ & $\begin{array}{l}\square \text { Yes } \\
\square \text { No }\end{array}$ \\
\hline $\begin{array}{l}\text { Did any medical staffs ever recommend pneumococcal } \\
\text { vaccines to you? }\end{array}$ & $\begin{array}{l}\square \text { Yes } \\
\square \text { No }\end{array}$ \\
\hline \multicolumn{2}{|l|}{ 4) COVID-19 vaccination } \\
\hline Did you receive the COVID-19 vaccine? & $\begin{array}{l}\square \text { Yes } \\
\square \text { No } \\
\end{array}$ \\
\hline $\begin{array}{l}\text { Did you ever get any knowledge regarding the COVID-19 } \\
\text { vaccines in the hospital or other medical institutions if you } \\
\text { had not received the COVID-19 vaccination? }\end{array}$ & $\begin{array}{l}\square \text { Yes, COVID-19 vaccines were recommended by the } \\
\text { clinicians } \\
\square \text { Yes, but COVID-19 vaccines were not recommended } \\
\text { by the clinicians } \\
\square \text { Yes, but the clinicians did not give definite } \\
\text { recommendation } \\
\square \text { No, I did not get any knowledge regarding the } \\
\text { COVID-19 vaccines }\end{array}$ \\
\hline $\begin{array}{l}\text { The reason why an individual did not accept COVID-19 } \\
\text { vaccination? }\end{array}$ & $\begin{array}{l}\square \text { worrying about the side effects } \\
\square \text { COVID-19 vaccines being not appropriate because of } \\
\text { COPD } \\
\square \text { activity inconvenience } \\
\square \text { others }\end{array}$ \\
\hline $\begin{array}{l}\text { 5) Did the COVID-19 epidemic and COVID-19 vaccination } \\
\text { have any impact on your intention to influenza vaccination? }\end{array}$ & $\begin{array}{l}\square \text { Yes, I would pay more attenuation to influenza } \\
\text { vaccination } \\
\square \quad \text { Yes, I would consider to receive influenza } \\
\text { vaccination } \\
\square \quad \text { Yes, I have decided to get influenza vaccination this } \\
\text { year } \\
\square \text { No, my intention to influenza vaccination was not } \\
\text { influenced }\end{array}$ \\
\hline
\end{tabular}

Figure I Vaccination uptake and knowledge of and intention to vaccination in the questionnaire. 
Table I Demographic and Clinical Characteristics $(n=264)$

\begin{tabular}{|c|c|}
\hline Characteristics & $\begin{array}{l}\text { Mean } \pm \text { SD or } \\
\text { n (\%) }\end{array}$ \\
\hline Age & $68.4 \pm 8.8$ \\
\hline \multicolumn{2}{|l|}{ Gender } \\
\hline Male & $236(89.4)$ \\
\hline Female & $28(10.6)$ \\
\hline \multicolumn{2}{|l|}{ Residence } \\
\hline Urban & $247(93.6)$ \\
\hline Rural area & $17(6.4)$ \\
\hline \multicolumn{2}{|l|}{ Education } \\
\hline Primary school or lower & $48(18.2)$ \\
\hline Middle school & $161(61.0)$ \\
\hline College & $18(6.8)$ \\
\hline University or higher & $37(14.0)$ \\
\hline \multicolumn{2}{|l|}{ Employment status } \\
\hline Currently working & $24(9.1)$ \\
\hline Retired & $220(83.3)$ \\
\hline Other & $20(7.6)$ \\
\hline \multicolumn{2}{|l|}{ Medical insurance } \\
\hline No insurance & $14(5.3)$ \\
\hline Urban Residents Medical Insurance & $196(74.2)$ \\
\hline Free Medical Service & $24(9.1)$ \\
\hline Medical Insurance outside Beijing & $30(11.4)$ \\
\hline \multicolumn{2}{|l|}{ Smoking status } \\
\hline Current smokers & $70(26.5)$ \\
\hline Former smokers & $160(60.6)$ \\
\hline Never smokers & $34(12.9)$ \\
\hline Smoking index (pack-year) ${ }^{a}$ & $35.0 \pm 21.8$ \\
\hline \multicolumn{2}{|l|}{ Modified MRC dyspnea scale } \\
\hline 0 & $32(12.1)$ \\
\hline I & $95(36.0)$ \\
\hline 2 & $78(29.6)$ \\
\hline 3 & $46(17.4)$ \\
\hline 4 & $13(4.9)$ \\
\hline $\begin{array}{l}\text { Frequency of hospitalization due to COPD } \\
\text { exacerbation in } 2019 \text { (/year) }\end{array}$ & $0.27 \pm 0.62$ \\
\hline $\begin{array}{l}\text { Frequency of hospitalization due to COPD } \\
\text { exacerbation in } 2020 \text { (/year) }\end{array}$ & $0.17 \pm 0.46$ \\
\hline \multicolumn{2}{|l|}{ Comorbidities } \\
\hline Diabetes mellitus & $40(15.2)$ \\
\hline Cardiovascular diseases & $86(32.6)$ \\
\hline Tumors & $18(6.8)$ \\
\hline Chronic liver or renal diseases & $5(1.9)$ \\
\hline Autoimmune diseases & $3(1.1)$ \\
\hline None of the above & $139(52.7)$ \\
\hline
\end{tabular}

(Continued)
Table I (Continued).

\begin{tabular}{|l|l|}
\hline Characteristics & $\begin{array}{l}\text { Mean } \pm \text { SD or } \\
\text { n (\%) }\end{array}$ \\
\hline Pharmacological treatment & \\
ICS/LABA & $121(56.0)$ \\
LAMA & $105(48.6)$ \\
LABA/LAMA & $22(10.2)$ \\
LABA/LAMA/ICS (fixed dose triple therapy) & $29(13.4)$ \\
SABA or SAMA & $13(6.9)$ \\
\hline
\end{tabular}

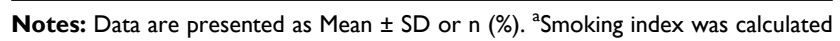
in current and former smokers.

Abbreviations: COPD, chronic obstructive pulmonary disease; MRC, Medical Research Council; ICS, inhaled corticosteroid; LABA, long-acting $\beta$-agonist; IAMA, long-acting muscarinic antagonist; SABA, short-acting $\beta$-agonist; SAMA, short-acting muscarinic antagonist.

Table 2 The Rate of Influenza, Pneumococcal and COVID-19 Vaccination $(n=264)$

\begin{tabular}{|l|l|}
\hline Vaccines & N (\%) of Vaccination \\
\hline Influenza vaccine & $60(22.7)$ \\
Pneumococcal vaccine & $15(5.7)$ \\
COVID-19 vaccine & $103(39.0 \%)$ \\
\hline
\end{tabular}

Note: Data are presented as $n$ (\%).

Abbreviation: COVID-19, coronavirus disease 2019.

$92(34.9 \%)$ of the patients reported that they had ever been recommended for influenza and pneumococcal vaccinations by medical staff, respectively.

In the patients who did not receive influenza vaccination $(\mathrm{n}=204)$, "worrying about the side effects" $(61 / 204$, $29.9 \%)$ and "do not think it necessary" (54/192, 26.5\%) were the most common reasons. Similarly, in the patients who did not receive pneumococcal vaccination $(\mathrm{n}=249)$, the most common reasons were the same $(61 / 249,24.5 \%$; $60 / 249,24.1 \%$, respectively) (Table 3 ).

Other reasons why an individual did not accept the vaccines were self-reported by the patients. These included having no knowledge of influenza or pneumococcal vaccines, allergic constitution, having other severe diseases, such as malignancies, and not recommended by the general practitioners (Table 3).

\section{Knowledge of and Attitude Towards COVID- 19 Vaccination}

Of the patients who did not receive COVID-19 vaccination $(\mathrm{n}=161), 31.7 \%(51 / 161)$ had made a decision to get 
Table 3 Reasons for the Patients Who Did Not Receive Influenza or Pneumococcal Vaccination

\begin{tabular}{|c|c|c|}
\hline & $\begin{array}{c}\text { Not } \\
\text { Receiving } \\
\text { Influenza } \\
\text { Vaccination } \\
(n=204)\end{array}$ & $\begin{array}{c}\text { Not Receiving } \\
\text { Pneumococcal } \\
\text { Vaccination } \\
(n=249)\end{array}$ \\
\hline Worry about the side effects & $61(29.9)$ & $61(24.5)$ \\
\hline Do not think it necessary & $54(26.5)$ & $60(24.1)$ \\
\hline Activity inconvenience & $16(7.8)$ & $13(5.2)$ \\
\hline Own expense for vaccination & $4(2.0)$ & $6(2.4)$ \\
\hline Others & $64(31.4)$ & $106(42.6)$ \\
\hline $\begin{array}{l}\text { Having no knowledge of the } \\
\text { vaccines }\end{array}$ & $50(78.1)$ & $87(82.1)$ \\
\hline Having other severe diseases & $9(14.1)$ & $9(8.5)$ \\
\hline Allergic constitution & $5(7.8)$ & $5(4.7)$ \\
\hline $\begin{array}{l}\text { Not recommended by the general } \\
\text { practitioners }\end{array}$ & $0(0.0)$ & $5(4.7)$ \\
\hline
\end{tabular}

Note: Data are presented as n (\%).

COVID-19 vaccination, while the remaining (68.3\%, 110/ 161) did not intend to get COVID-19 vaccination. Only $16.2 \%$ (26/161) reported that COVID-19 vaccines were recommended by clinicians, and most of them were not recommended for COVID-19 vaccination (47.8\%, 77/161) or did not get definite recommendations from clinicians (12.4\%, 20/161). 23.6\% (38/161) of them had no knowledge regarding COVID-19 vaccination. In those who did not intend to get COVID-19 vaccination $(n=110), 48.2 \%$
(53/110) thought that COVID-19 vaccines were not appropriate for them because of COPD and 30.9\% (34/110) worried about the side effects (Figure 2).

The uptake rate of COVID-19 vaccination in individuals receiving influenza vaccination in the past season was significantly higher than in those not receiving influenza vaccination $(61.7 \%$ vs $32.4 \%, P<0.001)$. Similarly, the individuals receiving pneumococcal vaccination in the past year had a greater rate of COVID-19 vaccination (73.3\% vs $36.9 \%, P=0.005)$.

\section{Impact of COVID-19 Pandemic and COVID-19 Vaccination on Intention and Attitude Towards Influenza Vaccination}

Of all the patients, over a half $(51.1 \%)$ reported that their intention to receive influenza vaccination was influenced by the COVID-19 pandemic. 34.5\% (91/264) would pay more attention to influenza vaccination, $12.1 \%(32 / 264)$ considered to receive influenza vaccination, and 4.5\% (12/ 264) had decided to get influenza vaccination this year. But, 48.9\% (129/264) thought that their attitude to influenza vaccination was not affected by the COVID-19 pandemic.

In patients who had not received influenza vaccination in the past season $(n=204)$, the rate of COVID-19 vaccine uptake was higher in those reporting that COVID-19 and COVID-19 vaccination did have a positive impact on their intention to receive influenza vaccination, as compared to

The patients who did not intend to get COVID-19 vaccination $(\mathrm{n}=110)$

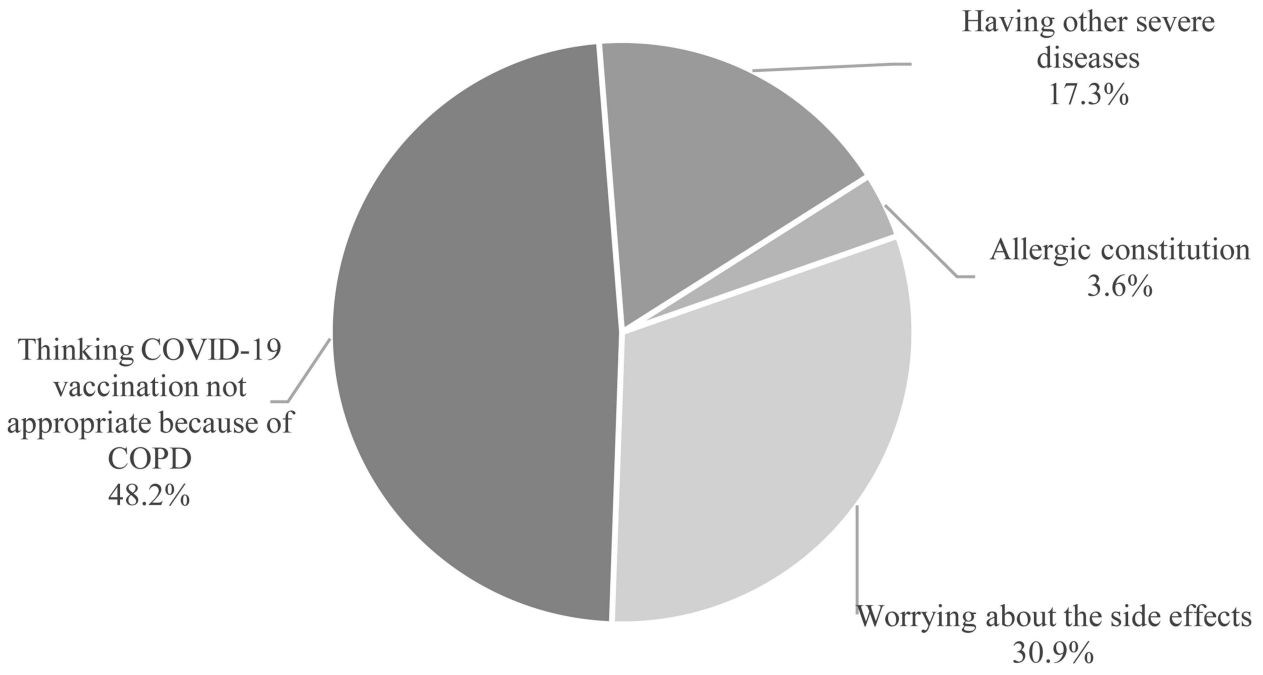

Figure 2 Distribution of the reasons why the patients did not intend to get COVID-19 vaccination $(n=110)$. 
Table 4 Factors Associated with the Change of Intention to Receive Influenza Vaccination After the COVID-19 Epidemic in Beijing $(n=204)^{a}$

\begin{tabular}{|c|c|c|c|c|c|c|}
\hline & \multicolumn{3}{|c|}{ Univariate Analysis } & \multicolumn{3}{|c|}{ Multivariate Analysis } \\
\hline & OR & $95 \% \mathrm{Cl}$ & $P$-value & OR & $95 \% \mathrm{Cl}$ & $P$-value \\
\hline Age $\geq 60$ years & 0.65 & $0.32-1.34$ & 0.241 & & & \\
\hline Education level & N/A & N/A & 0.746 & & & \\
\hline Current-/Ex-smoker & 0.89 & $0.37-2.16$ & 0.797 & & & \\
\hline$\geq 1$ comorbidities & 0.79 & $0.46-1.37$ & 0.407 & & & \\
\hline Maintaining long-term inhaled medications & 1.47 & $0.79-2.75$ & 0.220 & & & \\
\hline Knowing the benefit of influenza vaccine & 1.53 & $0.86-2.75$ & 0.151 & & & \\
\hline Knowing the subsidy policy of influenza vaccination in Beijing & 1.78 & $1.03-3.13$ & 0.039 & 1.45 & $0.77-2.7 \mid$ & 0.251 \\
\hline Influenza vaccine recommended by medical staffs & 1.76 & $0.98-3.19$ & 0.059 & 1.42 & $0.73-2.77$ & 0.299 \\
\hline COVID-19 vaccination & 2.39 & $1.17-3.86$ & 0.013 & 1.99 & $1.08-3.65$ & 0.027 \\
\hline
\end{tabular}

Notes: ${ }^{a}$ Data were analyzed in the patients who did not receive influenza vaccination in the past season $(2020 / 2021, n=204)$. Univariate analysis was performed by Chisquare test, while multivariate analysis was performed by binary logistic regression model. The change of intention to influenza vaccination in future was converted to a binary variable, which was recorded as "Yes" or "No". Except education level, the other variables included in the analysis were also converted to binary variables. The variables with $P<0.1$ in the univariate analysis were included in multivariate analysis.

Abbreviations: COVID-19, coronavirus disease 2019; OR, odds ratio; $\mathrm{Cl}$, confidence interval.

those reporting not $(40.8 \%$ vs $24.5 \%, P=0.013)$. Other factors associated with the change of intention to influenza vaccination are presented in Table 4. Knowing the subsidy policy of influenza vaccination in Beijing was statistically associated with the change of intention to influenza vaccination. After adjustment from the variables with $P<0.1$ in univariate analysis in Table 4 (ie "Knowing the subsidy policy of influenza vaccination in Beijing" and "influenza vaccination recommended by the medical staffs"), having COVID-19 vaccination remained independently associated with a positive change of intention to influenza vaccination in the logistic regression analysis.

\section{Discussion}

In this cross-sectional survey, we investigated the uptake rate of COVID-19 vaccines during the first vaccination campaign against COVID-19 among patients with COPD in Beijing for the first time. We found that the actual uptake rate of COVID19 vaccination was relatively low, although most of our patients would like to accept COVID-19 vaccination. To our surprise, nearly one half of the patients who did not receive COVID-19 vaccination had not been recommended for COVID-19 vaccination by their clinicians, which was most likely the main reason that COVID-19 vaccination rate was low among these patients. To our knowledge, there was no evidence regarding the effectiveness and safety of COVID-19 vaccination in patients with COPD, although a recent study demonstrated that the safety and tolerability of mRNA SARS-CoV-2/COVID-19 vaccine was good in severe asthma patients. ${ }^{30}$ Another study showed that the acceptance of COVID-19 vaccination in cancer patients was only $17.8 \%$ and a substantial proportion of them thought that COVID-19 vaccination may have negative effect on their cancer treatment. ${ }^{31}$ Therefore, doctors may be reluctant to recommend a new vaccine for those with underlying diseases such as COPD and malignancies. The role of medical advice in promoting vaccination campaign has been highlighted in some previous studies. ${ }^{32-35}$ Improving the knowledge of medical staff in hospitals and medical institutions regarding the effectiveness, safety and importance of COVID-19 vaccination was an important strategy for increasing vaccination acceptance and coverage. Meanwhile, our data showed that a substantial proportion of our patients did not have the necessary knowledge of and confidence in the effectiveness and safety regarding COVID19 vaccines, which also served as barriers to improving the coverage of COVID-19 vaccination.

In addition, we found that the uptake rate of COVID19 vaccination was much higher in patients who had ever received influenza vaccination in the past influenza season or received pneumococcal vaccination in the past year, indicating that the individuals who had been vaccinated with other vaccines might have better adherence and acceptance of COVID-19 vaccines. Previous studies also demonstrated that the individuals receiving influenza vaccination in the 2020-2021 influenza season were more likely to be vaccinated against COVID-19, ${ }^{36-38}$ which were similar to our study. We thought that this was reasonable since the attitudes and intentions to other vaccines would affect the acceptance of COVID-19 vaccines. 
As expected, we observed that most of our patients did change their attitude towards influenza vaccination after the COVID-19 epidemic in Beijing. Moreover, receiving COVID-19 vaccination was independently and positively associated with the improvement of intention to receive influenza vaccines in patients who did not receive influenza vaccination in the past year. These findings supported our hypothesis that COVID-19 pandemic and widespread acceptance of COVID-19 vaccination would play a positive role in increasing the awareness and acceptance of influenza vaccination in patients with COPD. A previous study also observed that over $90 \%$ of the elderly population presented a positive attitude towards pneumococcal vaccine during the COVID-19 pandemic $^{19}$ and this proportion was much higher than that reported in Chinese urban elderly population in 2014 (21.77\%). ${ }^{39}$

Nevertheless, it needed to be noted that the uptake rates of influenza (22.7\%) and pneumococcal (5.7\%) vaccines in the past year were very low in our patients, although most of them were aware of the subsidy policy providing free influenza vaccination to Beijing residents aging $\geq 60$ years, which was implemented since 2007, ahead of most cities in China ${ }^{40}$ Surveys conducted in Beijing found that the overall coverage rate of influenza vaccination was $20.6 \%$, but the rate in those aged $\geq 60$ years was $38.7 \%$ $49.3 \%,{ }^{41,42}$ which was higher than the rate in our study. Also, the uptake rate of pneumococcal vaccination in our study was even lower, compared to previous studies. ${ }^{12,43}$ Concerns about the side effects and the belief that the vaccines were unnecessary or ineffective were common reasons, which were consistent with the previous studies. $^{21,23}$ A lack of recommendation from healthcare workers was another reason in our survey, with less than a half of our patients being recommended for influenza or pneumococcal vaccination. Patient education program, media campaign, and the awareness of healthcare workers on the importance of vaccination were required to improve coverage, besides free vaccination policy.

There were several limitations in our study. The first was that the sample size was relatively small, and over $90 \%$ of the participants came from urban area. The coverage of vaccination may be different in some rural areas. A study conducted in Shanghai showed that the uptake rate in rural areas was higher for pneumonia vaccination but lower for influenza vaccination than the rate in urban areas. ${ }^{12}$ The second was that our patients were from seven tertiary hospitals in Beijing, while primary medical institutions were not included in our study. Compared with those only managed by primary care providers, patients referred for pulmonary subspecialty evaluation showed significantly higher coverage rates of influenza and pneumococcal vaccination. ${ }^{44}$ The third was that this survey study was conducted in Beijing, and therefore the results may not be appropriate to be generalized to other Chinese population. The fourth was that the COVID-19 vaccination program was still ongoing in China and the actual coverage rate of COVID-19 vaccination in 2021 needs to be further updated. Lastly, in our questionnaire, the phrasing "Did you know" might induce a positive answer, which might be prone to acceptability bias.

In conclusion, the uptake rate of COVID-19 vaccination in COPD patients in Beijing was 39.0\%, and that of influenza and pneumococcal vaccination was lower. Lack of recommendations from medical staff, and concerns about the effectiveness and side effects of vaccines were the main reasons against vaccination. Importantly, the COVID-19 pandemic and the COVID-19 vaccination campaign showed a significant, positive impact on patients with COPD in terms of influenza vaccination, one of the recommended measures for reducing exacerbation of COPD.

\section{Data Sharing Statement}

The data that supports the findings of this study will not be shared openly with other third parties due to contractual statements related to intellectual property, confidentiality, and proprietary rights.

\section{Ethics Approval and Informed Consent}

The study protocol was approved by the Independent Ethics Committee of the Peking University Third Hospital (IRB00006761-M2021379) which was the primary research institution of the present study. Informed consent was obtained from the patients or their close relatives. This study was conducted in accordance with the Declaration of Helsinki.

\section{Author Contributions}

All authors made substantial contributions to conception and design, acquisition of data, or analysis and interpretation of data; took part in drafting the article or revising it critically for important intellectual content; agreed to submit to the current journal; gave final approval for the 
version to be published; and agreed to be accountable for all aspects of the work.

\section{Funding}

This work was supported by the National Natural Science Foundation of China [No. 81700039].

\section{Disclosure}

The authors report no conflicts of interest in this work.

\section{References}

1. World Health Organization. Evidence-informed policy network: EVIPnet in action. Available from: http://www.who.int/evidence. Accessed November 10, 2021.

2. Soriano JB, Abajobir AA, Abate KH; GBD 2015 Chronic Respiratory Disease Collaborators. Global, regional, and national deaths, prevalence, disability-adjusted life years, and years lived with disability for chronic obstructive pulmonary disease and asthma, 1990-2015: a systematic analysis for the Global Burden of Disease Study 2015. Lancet Respir Med. 2017;5(9):691-706. doi:10.1016/ S2213-2600(17)30293-X

3. Global strategy for the diagnosis, management and PRevention of Chronic Obstructive Pulmonary Disease, Global Initiative for Chronic Obstructive Lung Disease (GOLD) 2021 report. Available from: http://www.goldcopd.org/. Accessed January 15, 2021.

4. Gershon AS, Chung H, Porter J, et al. Influenza vaccine effectiveness in preventing hospitalizations in older patients with chronic obstructive pulmonary disease. $J$ Infect Dis. 2020;221(1):42-52. doi:10. 1093/infdis/jiz419

5. Mohan A, Chandra S, Agarwal D, et al. Prevalence of viral infection detected by PCR and RT-PCR in patients with acute exacerbation of COPD: a systematic review. Respirology. 2010;15(3):536-542. doi:10.1111/j.1440-1843.2010.01722.x

6. Papi A, Bellettato CM, Braccioni F, et al. Infections and airway inflammation in chronic obstructive pulmonary disease severe exacerbations. Am J Respir Crit Care Med. 2006;173(10):11 14-1121. doi:10.1164/rccm.200506-859OC

7. World Health Organization. Influenza (Seasonal). Available from: http://www.who.int/en/news-room/fact-sheets/detail/influenza-(seaso nal). Accessed April 15, 2021.

8. Mulpuru S, Li L, Ye L, et al. Effectiveness of influenza vaccination on hospitalizations and risk factors for severe outcomes in hospitalized patients with COPD. Chest. 2019;155(1):69-78. doi:10.1016/j. chest.2018.10.044

9. Bao W, Li Y, Wang T, et al. Effects of influenza vaccination on clinical outcomes of chronic obstructive pulmonary disease: a systematic review and meta-analysis. Ageing Res Rev. 2021; 68:101337. doi:10.1016/j.arr.2021.101337

10. Walters JA, Tang JN, Poole P, Wood-Baker R. Pneumococcal vaccines for preventing pneumonia in chronic obstructive pulmonary disease. Cochrane Database Syst Rev. 2017;1(1):CD001390. doi:10.1002/14651858.CD001390.pub4

11. Fan J, Cong S, Wang N, et al. Influenza vaccination rate and its association with chronic diseases in China: results of a national cross-sectional study. Vaccine. 2020;38(11):2503-2511. doi:10.1016/ j.vaccine.2020.01.093

12. Wang Y, Cheng M, Wang S, et al. Vaccination coverage with the pneumococcal and influenza vaccine among persons with chronic diseases in Shanghai, China, 2017. BMC Public Health. 2020;20 (1):359. doi:10.1186/s12889-020-8388-3
13. Wang YH, Ye KY, Wang SY, et al. [Real world study of influenza vaccination intervention among key population of chronic disease management in Shanghai community]. Zhonghua Yu Fang Yi Xue Za Zhi. 2020;54(4):425-429. Chinese. doi:10.3760/cma.j.cn11215020191031-00828

14. Hsu DJ, North CM, Brode SK, Celli BR. Identification of barriers to influenza vaccination in patients with Chronic Obstructive Pulmonary Disease: analysis of the 2012 behavioral risk factors surveillance system. Chronic Obstr Pulm Dis. 2016;3(3):620-627. doi:10.15326/ jcopdf.3.3.2015.0156

15. Mowls DS, Cheruvu VK, Zullo MD. Influenza vaccination in adults with chronic obstructive pulmonary disease: the impact of a diagnostic breathing test on vaccination rates. PLoS One. 2013;8 (6):e67600. doi:10.1371/journal.pone. 0067600

16. Vozoris NT, Lougheed MD. Influenza vaccination among Canadians with chronic respiratory disease. Respir Med. 2009;103(1):50-58. doi:10.1016/j.rmed.2008.08.004

17. Garrastazu R, García-Rivero JL, Ruiz M, et al. Prevalence of influenza vaccination in Chronic Obstructive Pulmonary Disease patients and impact on the risk of severe exacerbations. Arch Bronconeumol. 2016;52(2):88-95. doi:10.1016/j.arbres.2015.09.001

18. Fan J, Cong S, Wang N, et al. [Pneumococcal vaccination rate in chronic obstructive pulmonary disease patients aged 40 years or older in China, 2014-2015]. Zhonghua Liu Xing Bing Xue Za Zhi. 2020;41 (7):1028-1033. Chinese. doi:10.3760/cma.j.cn112338-20200124-00 056

19. Zhang M, Chen $\mathrm{H}$, Wu F, et al. Heightened willingness toward pneumococcal vaccination in the elderly population in Shenzhen, China: a cross-sectional study during the COVID-19 pandemic. Vaccines. 2021;9(3):212. doi:10.3390/vaccines 9030212

20. Huang HH, Chen SJ, Chao TF, et al. Influenza vaccination and risk of respiratory failure in patients with chronic obstructive pulmonary disease: a nationwide population-based case-cohort study. $J$ Microbiol Immunol Infect. 2019;52(1):22-29. doi:10.1016/j.jmii.2017.08.014

21. Joseph C, Elgohari S, Nichols T, Verlander N. Influenza vaccine uptake in adults aged 50-64 years: policy and practice in England 2003/2004. Vaccine. 2006;24(11):1786-1791. doi:10.1016/j.vaccine. 2005.10 .024

22. Hara M, Sakamoto T, Tanaka K. Influenza vaccine effectiveness among elderly persons living in the community during the 20032004 season. Vaccine. 2008;26(50):6477-6480. doi:10.1016/j. vaccine.2008.06.035

23. Kwong EW, Lam IO, Chan TM. What factors affect influenza vaccine uptake among community-dwelling older Chinese people in Hong Kong general outpatient clinics. J Clin Nurs. 2009;18 (7):960-971. doi:10.1111/j.1365-2702.2008.02548.x

24. Alqahtani JS, Oyelade T, Aldhahir AM, et al. Prevalence, severity and mortality associated with COPD and smoking in patients with COVID-19: a rapid systematic review and meta-analysis. PLoS One. 2020;15(5):e0233147. doi:10.1371/journal.pone.0233147

25. Guan WJ, Liang WH, Zhao Y, et al. Comorbidity and its impact on 1590 patients with COVID-19 in China: a nationwide analysis. Eur Respir J. 2020;55(5):2000547. doi:10.1183/13993003.00547-2020

26. Wu Z, Hu Y, Xu M, et al. Safety, tolerability, and immunogenicity of an inactivated SARS-CoV-2 vaccine (CoronaVac) in healthy adults aged 60 years and older: a randomised, double-blind, placebo-controlled, Phase $1 / 2$ clinical trial. Lancet Infect Dis. 2021;21(6):803-812. doi:10.1016/S1473-3099(20)30987-7

27. Logunov DY, Dolzhikova IV, Shcheblyakov DV, et al. Safety and efficacy of an rAd26 and rAd5 vector-based heterologous prime-boost COVID-19 vaccine: an interim analysis of a randomised controlled Phase 3 trial in Russia. Lancet. 2021;397 (10275):671-681. doi:10.1016/S0140-6736(21)00234-8

28. Baden LR, El Sahly HM, Essink B, et al. Efficacy and safety of the mRNA-1273 SARS-CoV-2 Vaccine. $N$ Engl J Med. 2021;384 (5):403-416. doi:10.1056/NEJMoa2035389 
29. Bestall JC, Paul EA, Garrod R, Garnham R, Jones PW, Wedzicha JA. Usefulness of the Medical Research Council (MRC) dyspnoea scale as a measure of disability in patients with chronic obstructive pulmonary disease. Thorax. 1999;54(7):581-586. doi:10.1136/thx.54.7. 581

30. Caminati M, Guarnieri G, Batani V, et al. COVID-19 vaccination in patients with severe asthma on biologic treatment: safety, tolerability, and impact on disease control. Vaccines. 2021;9(8):853. doi:10.3390/ vaccines 9080853

31. Chan WL, Ho YT, Wong CK, et al. Acceptance of COVID-19 vaccination in cancer patients in Hong Kong: approaches to improve the vaccination rate. Vaccines. 2021;9(7):792. doi:10.3390/vaccines 9070792

32. Santos-Sancho JM, Jimenez-Trujillo I, Hernández-Barrera V, et al. Influenza vaccination coverage and uptake predictors among Spanish adults suffering COPD. Hum Vaccin Immunother. 2012;8(7):9 38-945. doi:10.4161/hv.20204

33. Yeung MP, Lam FL, Coker R. Factors associated with the uptake of seasonal influenza vaccination in adults: a systematic review. J Public Health. 2016;38(4):746-753. doi:10.1093/pubmed/fdv194

34. Li A, Chan YH, Liew MF, Pandey R, Phua J. Improving influenza vaccination coverage among patients with COPD: a pilot project. Int J Chron Obstruct Pulmon Dis. 2019;14:2527-2533. doi:10.21 47/COPD.S222524

35. Bazargan $\mathrm{M}$, Wisseh $\mathrm{C}$, Adinkrah $\mathrm{E}$, et al. Influenza vaccination among underserved African-American older adults. Biomed Res Int. 2020;2020:2160894. doi:10.1155/2020/2160894

36. Belingheri M, Roncalli M, Riva MA, Paladino ME, Teruzzi CM. COVID-19 vaccine hesitancy and reasons for or against adherence among dentists. J Am Dent Assoc. 2021;152(9):740-746. doi:10. 1016/j.adaj.2021.04.020
37. Burke PF, Masters D, Massey G. Enablers and barriers to COVID-19 vaccine uptake: an international study of perceptions and intentions. Vaccine. 2021;39(36):5116-5128. doi:10.1016/j.vaccine.2021.07.056

38. Alibrahim J, Awad A. COVID-19 vaccine hesitancy among the public in Kuwait: a cross-sectional survey. Int $J$ Environ Res Public Health. 2021;18(16):8836. doi:10.3390/ijerph18168836

39. Liu S, Xu E, Liu Y, et al. Factors associated with pneumococcal vaccination among an urban elderly population in China. Hum Vaccin Immunother. 2014;10(10):2994-2999. doi:10.4161/21645515.2014. 972155

40. Zhang Y, Muscatello DJ, Wang Q, Yang P, Wu J, MacIntyre CR. Overview of influenza vaccination policy in Beijing, China: current status and future prospects. J Public Health Policy. 2017;38 (3):366-379. doi:10.1057/s41271-017-0079-7

41. Wu S, Su J, Yang P, et al. Factors associated with the uptake of seasonal influenza vaccination in older and younger adults: a large, population-based survey in Beijing, China. BMJ Open. 2017;7(9): e017459. doi:10.1136/bmjopen-2017-017459

42. Lv M, Fang R, Wu J, et al. The free vaccination policy of influenza in Beijing, China: the vaccine coverage and its associated factors. Vaccine. 2016;34(18):2135-2140. doi:10.1016/j.vaccine.2016.02.032

43. Fekete M, Pako J, Nemeth AN, Tarantini S, Varga JT. Prevalence of influenza and pneumococcal vaccination in chronic obstructive pulmonary disease patients in association with the occurrence of acute exacerbations. J Thorac Dis. 2020;12(8):4233-4242. doi:10.21037/ jtd-20-814

44. Ehteshami-Afshar S, Crothers K, Rodwin B, Bade B, Brandt C, Akgün KM. Does pulmonary subspecialty referral from primary care affect the adherence to vaccination recommendations in COPD patients. Respir Res. 2021;22(1):50. doi:10.1186/s12931021-01639-6

\section{Publish your work in this journal}

The International Journal of COPD is an international, peer-reviewed journal of therapeutics and pharmacology focusing on concise rapid reporting of clinical studies and reviews in COPD. Special focus is given to the pathophysiological processes underlying the disease, intervention programs, patient focused education, and self management protocols. This journal is indexed on PubMed Central, MedLine and CAS. The manuscript management system is completely online and includes a very quick and fair peer-review system, which is all easy to use. Visit http://www.dovepress.com/testimonials.php to read real quotes from published authors. 